\title{
An Approach for Investigating Perspective of Cloud Software-as-a-Service (SaaS)
}

\author{
Sushil Bhardwaj \\ Assistant Professor \\ RIMT-Regional Institute of Mgmt. \& \\ Technology, Mandi Gobindgarh, \\ Punjab, India-147301
}

\author{
Leena Jain \\ Assistant Professor \\ RIMT-Regional Institute of Mgmt. \& \\ Technology, Mandi Gobindgarh, \\ Punjab, India-147301
}

\author{
Sandeep Jain \\ M. Tech Student, M.M.University, \\ Mullana, Ambala, India-133203
}

\begin{abstract}
Cloud Computing extend the areas of virtualization, clustering, IT management, Web Architecture, Services-Oriented Architecture (SOA) and brings new dimension in extending utility computing. The primary aim of Cloud Computing is to provide mobility deployment of web-based application by means of easily accessible tools and interfaces for using and manipulating infrastructure. Cloud-based services integrate globally scattered resources, which offer its users seamless services without any glitches. There are three general categories of services offered in cloud computing. They are Infrastructure-as-a-Service (IaaS), Platform-as-a-Service (PaaS), and Software-as-a-Service (SaaS). SaaS is becoming an increasingly ubiquitous software delivery model that support implementation of service-oriented architecture using Web services technologies. With SaaS gaining mainstream popularity, enhanced by the advent of web based computing options and virtualization platforms, the enterprise infrastructure is rapidly expanding into a large computing blurb- a 'computing cloud'. SaaS is the key setting for the rapid development that Cloud Computing is creating. In this paper we investigated SaaS by describing their characteristics, reasons for adoption and applications. SaaS model make possible for every customer to take advantages of provider's latest technological features without the burden of software maintenance, management, updates and upgrades. This paper also identifies the responsibilities of SaaS provider and the benefits to SaaS consumer.
\end{abstract}

\section{General Terms}

Cloud Computing, Software-as-a-Service.

\section{Keywords}

Cloud computing, Customer, IaaS, PaaS, Provider, SaaS.

\section{INTRODUCTION}

Cloud computing means Internet ('Cloud') based development and use of computer technology ('Computing'). It is computing technology where IT-related capabilities are provided "as a service", allowing users to access web based tools and application "in the cloud" without knowledge of, underlying technology infrastructure that supports them. According to analyst firm Gartner, cloud computing is "a style of computing whose massively scalable and elastic, IT-related capabilities are provided 'as a service' to external customers using Internet technologies". Cloud Computing accomplish a purpose of high performance, high scalability, low infrastructure cost, better availability and better utilization of IT infrastructure by clustering the inexpensive computers closely together in a data center and connected to other similar data centers located globally as close to the users as possible. With the growth in Internet usage, the proliferation of mobile devices, and the need for energy and processing efficiency, the stage has been set for a different computing model - the idea of computing as a utility [1]. Cloud computing, originated in the private sector where virtualization technology and large data centers have been turned into the foundation for products and services to be resold [2] and consist of multiple companies, multiple servers, and multiple networks [3]. In practice, cloud service providers tend to offer range of services in a cloud computing environment. These can be divided into three categories: software as a service, platform as a service and infrastructure as a service. While SaaS is by far the most familiar and prolific type of cloud computing implementation today, other types are also rapidly gaining recognition as enterprises are looking forward for cost and expertise advantages of each.

Software-as-a-Service (SaaS) may be described as a process by which Application Service Provider (ASP) provide different software applications over the Internet leveraging cloud infrastructure on "pay-as-you-go" pricing structure. This makes the customer to get rid of installing and operating the application on own computer. It also eliminates the tremendous load of software maintenance; continuing operation, safeguarding and support. SaaS vendor advertently takes responsibility for deploying and managing the IT infrastructure (servers, operating system software, databases, data center space, network access, power and cooling, etc.) and processes (infrastructure patches/upgrades, application patches/upgrades, backups, etc.) required to run and manage the full solution [4]. Software as a service features a complete application offered as a service on demand. A single instance of the software runs on the cloud and services multiple end users or client organizations. The great benefit of SaaS is the ability to run the most recent version of the application [5].

\section{LITERATURE REVIEW}

Cloud Computing provides a comprehensive service management solution to simplify customers' cloud journey to deliver cloud services with speed, flexibility, scale, and security [6]. Cloud systems [7] have recently emerged as a "new paradigm for the provision of computing infrastructure" for a wealth of applications [8]. By adopting the best IT infrastructure and service automation, 
Service Providers (SP), are freed from the burden of setting up and managing underlying hardware and software platforms required by their services. These resources are provisioned by the cloud platform, offered by a Cloud Provider (CP). Software-as-aService (SaaS) helps organizations avoid capital expenditure and pay for the functionality as an operational expenditure [9]. SaaS eliminates customer worries about application servers, storage, application development and related, common concerns of IT [10] and enables global access, significant cost reductions, and simplified operations for clients [11]. Applications are no longer installed locally on a user's desktop PC; instead, upgrades, licensing and version control, metering, support and provisioning are all managed at the server level [12]. SaaS approach can offer a way to collect and aggregate information automatically from a full range of the company's own systems such as enterprise resource planning (ERP), customer relationship management (CRM), supply chain management (SCM), payroll and others applications or data sources for middle size companies [13]. It can be adopted as an excellent outsourcing model since it exhibits the technological and economic benefits of IT services [14]. SaaS ability to have access to powerful technologies, with a minimal financial commitment has opened new vistas of productivity and competition to small to mid sized organizations [15]. IT/network professionals [16] should view SaaS as an opportunity to reduce the hassles of deploying and maintaining common business applications.

\section{UNDERSTANDING SAAS}

SaaS is currently the most popular and prolific type of cloud computing service because of its high flexibility and scalability, high performance with better availability, vast services and less maintenance. Yahoo mail, Google docs, ERP, BPM and CRM applications are all instances of SaaS. With a SaaS CRM all that customer need to do is register on a subscription basis, login to the central system and select the features that customer want, and any additional databases and applications if required and import any existing customer data. End user is free to use the service from anywhere with availability of application and data host by service providers. SaaS is gaining mainstream recognition in enterprises, because of very effective in lowering the costs of business as it provides the business an access to applications at a cost normally far cheaper than a licensed application fee which is possible due to its monthly fees based revenue model. There are some very popular service providers out there such as Salesforce.com, NetSuite or Aplicor. These SaaS solutions are normally manufactured by the vendor, often deployed in a multi-tenant supporting environment, provides standard based API's and SLA guarantees accompanied with a wide range of professional services.

Characteristics of SaaS include:

- All of the activities are managed from a central location rather than at each user's individual location, allowing modifications and troubleshooting to be accomplished quickly by the application vendor and eliminating the need for end-user upgrades or patches.

- Application are network based so that the business user free to use the service from anywhere that they choose using virtually any type of electronic device. Each application is pay-per-usage basis, allowing the business owner to predict their budget for the usage of number of applications according to business need.

- Application delivery typically based on one-to-many model comprise of (single instance, multi-tenant architecture) where an application is shared across multiple user.

- Automated and centralized updating eliminates the need for end-users to download patches and upgrades.

- Managing Complexity while reducing software costs.

- SaaS make possible to have regular integration with a large network of software which can communicate in the form of a mashup, or in the form of a platform.

- SaaS is highly efficient as Multi-tenant structural design makes the source code is same for every customer.

- Unlike traditional apps where customization means; by simple configuration, SaaS can meet any requirement such as functional, data integration etc.

- Any new tech-innovation is easily integrated by the service provider; the source code is same for every customer and is available for all the subscribers.

\section{SOFTWARE AS A SERVICE MODEL}

The software as a service model offers a high level description of the distributed data architecture of software delivery which allows vendors to develop, host and operate software for customer use. With SaaS Architecture, a provider licenses an application to customers on subscription based service delivery. It allows customer to require a computer or a server with internet access to download the application and utilise the software, which make customer to get rid of purchasing expensive hardware / software to run an application. It also allows the software to be licensed for either a single user or for a whole group of users.

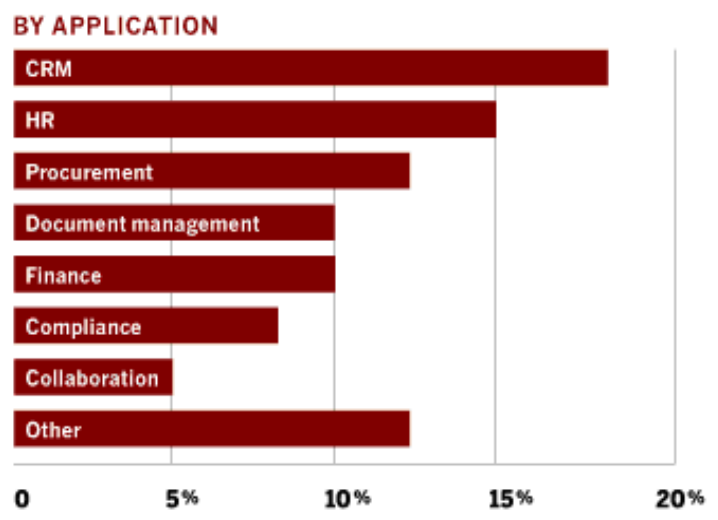

Figure 1. \%age of Application delivered in SaaS Model [17]

Software as a service Architecture (SaaS Architecture) has now become common by businesses for tasks such as ERP, CRM, computerised HR, invoicing, service desk management, Procurement, workflow systems, document management and many more. The usage of applications delivered as a service fall mainly in three areas: CRM, HR and procurement as shown in Figure 1. With SaaS an entire finished application is not owned by customer, but it can be accessible on-demand from some SaaS vendor. The application exists in the cloud is now web application 
and can be consumed from any browser. Therefore, the customer of a SaaS vendor is the end user.

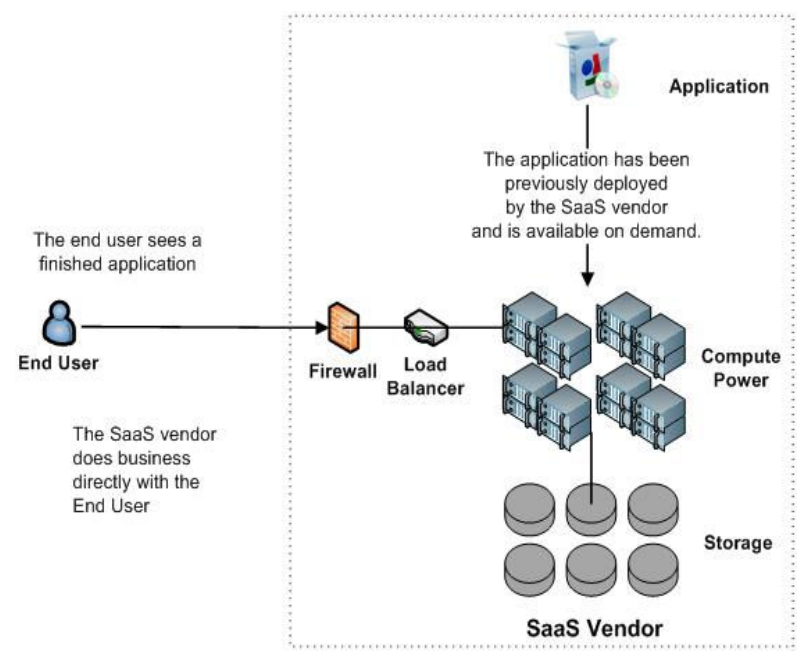

Figure 2. Software as a Service [18]

As shown in Figure 2. SaaS vendor is not only responsible for providing the service of data centers ( compute power, storage, and networking infrastructure) required to run the application, it also offer an entire application to the end user. Now the SaaS vendor may approach a third party PaaS and IaaS vendor to provide virtualization infrastructure. The software application may be implemented in such a way that enable users to access systems using a web browser, avoiding capital expenditure on infrastructure that is typically provided by a third-party.

\section{SAAS VENDOR AND CUSTOMER}

Software as a Service is a new delivery model which provides high degree of flexibility to both the provider and the customers. SaaS provider remotely hosts and manages software applications (for example, CRM, HR, Procurement, e-mail, word processing, and spreadsheets) for its customers and provides initial and ongoing support services. The cloud service consumer needs simple interface software, like a simple web browser to be run on their side and the service provider needs integrated IT resources so their usage is optimized. SaaS eliminates customer worries about application servers, storage, application development and related, common concerns of IT. It also enables every customer to benefit from the vendor's latest technological features without the disruptions, avoiding the onus of operating, supporting and maintaining applications and costs associated with software updates, upgrades and safeguards. Although low cost initially drove the SAAS market, today SAAS vendors are recognizing that reliability, scalability, and uptime are the key factors that drive long-term customer satisfaction [19]. SaaS has re-energized the software market, and has granted enterprise users an extra choice.

\subsection{SaaS Provider's Responsibilities}

- Responsible for running and managing servers, power and cooling, network access, data center space etc. SaaS also maintain operating system software, databases, installation of updates, ongoing backups, and more.

- Deploy web based applications to easily provision software for customers on demand.

- Typically has a multi tenant model of application with room for customization for each customer.

- Use virtualization infrastructure (network, application, dev platform, server, storage).

- Centralized controlled software deployment reduces help desk calls and support costs.

- Provide end users access to highly qualified and certified security professionals and technologies for safeguarding application breaches and attacks.

- Eases the process of cloning applications on additional infrastructure instances.

- Have well defined service level agreements with customers on "availability of infrastructure services".

- Reserve capacity to handle any spikes, surges and sags in usage, outages, or network mishaps.

- Provide the latest version of the application software to the customer.

- Provider takes care of hosting and managing the production operations.

- Ensuring the security and privacy of client data.

- Have the ability to gather comprehensive information about flaws, performance and usage patterns to improve their product.

- Responsible to deliver reliable and secure services according to requirement of their customers.

- Collaboration across Business Units or other enterprises.

- Implementing, personalizing and customizing business workflow.

- To continually improve their offering as well as their help desk customer service.

\subsection{Benefits to SaaS Consumer}

- Own the business logic and uses the providers software to implement the logic by fine tuning \& customizing the applications.

- Own the development platforms, hardware \& high degree of provisioning \& maintaining the dev platform, OS \& hygiene facts like space, power etc.

- Low variable cost based on usage instead of upfront fixed cost.

- Can be quickly upgraded to the latest releases without the traditional hassles of deployment an installation.

- Software is subscribed on annual or a monthly fee and not purchased; therefore expenses are not front loaded.

- Consistent few changes and feedback that add up over time instead of monster patch and upgrade that cost consumer's time and money to implement.

- Rapid and flawless platform extension, geographic expansion and growth, and worry-free bandwidth.

- Improved reliability, performance and efficiency.

- Enhanced productivity and faster deployment.

- Access to on-demand application anywhere, anytime. 
- Does not need to license and support the software in the traditional fashion.

- Does not have to purchase and support the infrastructure that the application runs upon.

\section{CONCLUSION}

By integrating all of the application software, data center, database, IT infrastructure and services together in a web-based, multi-tenant on demand delivery model, SaaS vendors can provide assurance to customers with economies of and skill that was one of the biggest challenges for traditional, on-premise deployments. SaaS shifts the onus of deployment, operation, management, support and successfully operation of the application from the customer to the vendor. From different perspectives: the infrastructure, academic research, design approaches and use cases, SaaS has moved beyond the tipping point from standalone, cost-driven software functionality to sophisticated, integrative, business-process-driven platforms \& services and accelerating into mainstream adoption. With the maturation of Software as a Service, we can expect to see more hybrid architectures, revenue generating opportunities, service offering, pricing models and rich set of applications. Table 1 summarizes Software as a Service. And of course, the biggest challenge for SaaS would be to gain customer's confidence and it can be achieved by implementing efficient application-level security mechanism, with proper definition of SLA guarantees and many more. However SaaS has tremendous potential to meet growing demand for business, industries and entire economics.

Table 1. SaaS Summary

\begin{tabular}{|l|l|}
\hline Offering & $\begin{array}{l}\text { Companies host applications in the cloud that } \\
\text { many users access through Internet connections. } \\
\text { The service being sold or offered is a complete } \\
\text { end-user application or Finished application. }\end{array}$ \\
\hline Customer & End User \\
\hline $\begin{array}{l}\text { Unit of } \\
\text { deployment }\end{array}$ & $\begin{array}{l}\text { The SaaS vendor does business directly with the } \\
\text { End User }\end{array}$ \\
\hline $\begin{array}{l}\text { Pricing } \\
\text { structure }\end{array}$ & Pay as you go cost model. Per user per month. \\
\hline Examples & $\begin{array}{l}\text { Salesforce's on-demand CRM, Bussiness Apps } \\
\text { from Microsoft, IBM, Google, and McAfee et. } \\
\text { instant messaging from AOL, Yahoo and Google, } \\
\text { and VoIP from Vonage and Skype. }\end{array}$ \\
\hline
\end{tabular}

\section{REFERENCES}

[1] Wyld, D. C. 2009, "The Utility Of Cloud Computing As A New Pricing - And Consumption - Model for Information Technology", International Journal Of Database Management Systems (IJDMS), Vol.1 (1), pp. 1-20.

[2] Rings, T., Caryer, G., Grabowski, J. G. J., Kovacikova, T., Schulz, S., and Rees, I. S. 2009, "Grid and Cloud Computing: Opportunities for Integration with the Next Generation Network", J. Grid Computing, Vol. 7, pp. 375393.

[3] Mirashe, S. P. and Kalyankar, N.V. 2010, "Cloud Computing”, Journal of Computing, Vol. 2(3), pp. 78-82.
[4] Agarwal, S. and McCabe, L. 2010, "The TCO Advantages of SaaS-Based Budgeting, Forecasting \& Reporting”, A Hurwitz white paper, Available : www.hurwitz.com

[5] Thomas, D. 2008, "Enabling Application Agility - Software as A Service, Cloud Computing and Dynamic Languages", in Journal of Object Technology, Vol. 7(4), pp. 29-32.

[6] Dodani, M. 2009, "The Silver Lining of Cloud Computing", J. Object Technology, Vol. 8(2), pp 29-38.

[7] Buyya, R., Yeo, C. S., Venugopal, S., Broberg J. and Brandic, I. 2009, "Cloud computing and emerging IT platforms: vision, hype and reality for delivering computing as the 5th utility", FGCS, 25(6), pp. 599-616.

[8] Grossman, R.L., Gu, Y., Sabala M. and Zhang W. 2009, "Compute and storage clouds using wide area high performance networks", Future Generation Computer Systems, 25 (2), pp. 179-183.

[9] Godse, M., and Mulik, S. 2009, "An Approach for Selecting Software-as-a-Service (SaaS) Product," In Proc. of IEEE International Conference on Cloud Computing, pp.155-158.

[10] Burford, D. 2010, "Cloud Computing: A Brief introduction", A LAD Enterprizes Inc. White paper,. Available online: www.ladenterprizes.com

[11] Clair, G. S. 2008, "Software-as-a-Service (SaaS): Put the Focus on the KM/Knowledge Services Core Function", AN EOS International white paper.

[12] Greschler, D. and Mangan, T. 2002, "Networking lessons in delivering :Software as a Service", International Journal of Network Management, Vol. 12(6), pp. 339 - 345.

[13] Ventana Research white paper, "Information Management For Midsize Companies", Available online : www.ventanaresearch.com

[14] Chou, D. C. and Chou, A. Y. 2007, " Analysis of a new information systems outsourcing practice: software-as-aservice business mode", International Journal of Information Systems and Change Management, Vol. 2(4), pp. 392 - 405.

[15] Weston, R. and Kaviani, S. 2009, "A Systematic Approach to Selecting a Software-as-a-service Vendor", A Hyper Office Inc. white paper,. Available : www.hyperoffice.com

[16] Kaplan, J. M. 2007, "SaaS: Friend Or Foe?", Business Communications Review, pp. 48-53, Available : http://www.wyvilsystems.com/newsap/pdf/saas-friend-orfoe.pdf

[17] Gruman, G. 2007, "The Truth About Software as a Service (SaaS)", Available online : http://www.cio.com/article/109706/The_Truth_About_Softw are_as_a_Service_SaaS

[18] Pijanowski, K. 2009, "Understanding public clouds: IaaS, PaaS, SaaS" on KeithPij.com, Available online : http://www.keithpij.com/Home/tabid/36/EntryID/27/Default. aspx

[19] Nuclear Research Inc. "Business Critical: Software-as-aservice Vendor Strategies", November 2007. Available online: www.NuclearResearch.com. 